\title{
Conventional and modified hydrodistillation method for the extraction of glucosinolate hydrolytic products: a comparative account
}

\author{
Rohit Arora ${ }^{1}$, Bikram Singh ${ }^{2}$, Adarsh Pal Vig ${ }^{1}$ and Saroj Arora ${ }^{*}$
}

\begin{abstract}
Eruca sativa is extensively used as raw and its oil is also used for cooking due to its exceptional flavour. The volatile nature of the hydrolytic products of glucosinolates makes the extraction difficult. The hydrodistillation method used previously yield very less amount of the extract as well as the absence of stirring in the round bottom flask causes burning of both the crushed seeds and the flask. To overcome these drawbacks, a method has been developed using magnetic stirrer and hot plate. The yield and composition of hydrolytic products in the extract with the modified method was increased along with an increase in the amount of major hydrolytic products as seen by GC-MS. This method thus has immense potential in pharmaceutical industries, due to the ease of extraction and isolation.
\end{abstract}

Keywords: Hydrodistillation, Magnetic stirrer with hot plate, Glucosinolates, Isothiocyanates, Erucin, GC-MS

\section{Background}

Eruca sativa- an annual herb of Mediterranean origin is rich in glucosinolates and is commonly known as arugula, rocket salad, rugula or taramira (Khoobchandani et al. 2010; Arora et al. 2014a, b). Its aerial portion has been used extensively in most parts of the world as salads. The oil obtained from their seeds is used in pickles and for cooking purpose. A number of reports are available that signify the biological importance of the glucosinolate hydrolytic products (Khoobchandani et al. 2010; Vig et al. 2009). These varied biological activities form the basis for developing the appropriate methods to achieve their maximum yield as well as number. A thorough literature survey reveals that although cold as well as hot extraction methods were used to obtain the valuable glucosinolate hydrolytic products (GHPs) from this plant, but it was seen that cold extraction methods were time consuming, gave a lower yield and that too with other unwanted

\footnotetext{
*Correspondence: sarojarora.gndu@gmail.com

1 Department of Botanical and Environmental Sciences, Guru Nanak Dev University, Amritsar, Punjab 143005, India

Full list of author information is available at the end of the article
}

compounds (other than glucosinolate hydrolytic products). On the other hand, the volatile nature of the compounds made hydrodistillation an important choice for the extraction. It gave a much higher yield in lesser time with lesser number of undesirable compounds. The only problem with this method was that it was not effective for the extraction of compounds from seeds. The reason being that the seeds when crushed absorb a lot of water and become heavier, thus crushed seeds settle down at the bottom of the round bottom flask. This causes the burning of the seed powder as well as the flask. The burning of the seed powder affects the yield as well as number of GHPs obtained.

In order to get rid of the above problems, a number of methods were used viz. microwave assisted and supercritical fluid based hydrodistillation (Arranz et al. 2015; Patra et al. 2015). Although the methods were effective but they involve the use of complex and highly expensive instruments. Keeping these facts in mind, a hydrodistillation method with magnetic stirrer and hot plate was developed that involved cheaper and simple instrument and gave much higher yield in lesser time. Further, the 
amount of the major components of the extract was very high making it easier to isolate them.

\section{Methods}

\section{Conventional hydrodistillation}

The conventional hydrodistillation was done following the method given by Blazevic and Mastelic (Blazevic and Mastelic 2009). In this, 50 g seeds of Eruca sativa (Mill.) Thell. var. RTM-1212 (procured from Sri Karan Narendra College of Agriculture, Jobner, Rajasthan, India), were crushed and added to $1000 \mathrm{ml}$ distilled water (DW) in a round bottom flask. The flask was then kept in a heating mantle and the Clevenger apparatus was attached (Fig. 1a). The mixture was allowed to boil at $100^{\circ} \mathrm{C}$ and then the temperature was reduced to $60^{\circ} \mathrm{C}$ and kept for $3 \mathrm{~h}$. The oil and water obtained was collected in a separation flask and the GHPs were obtained by fractionation using AR grade dichloromethane (DCM). The solvent was passed through anhydrous sodium sulphate and evaporated under vacuum at $30^{\circ} \mathrm{C}$, using rotary evaporator (Buchi R210). It was redissolved in GC grade DCM and passed through $0.22 \mu \mathrm{m}$ filter prior to GC-MS injection.

\section{Modified hydrodistillation}

The modified hydrodistillation method involved a magnetic stirrer with hotplate (Spinot, Tarsons Products Pvt. Ltd., New Delhi, India). Here, 50 g crushed seeds of Eruca sativa (Mill.) Thell. var. RTM-1212 were added to $1000 \mathrm{ml} \mathrm{DW}$ in a flat bottom flask containing a magnetic stir bar. The flask was attached to a clamp stand and the Clevenger apparatus was attached to it (Fig. 1b). The mixture was allowed to boil at $100{ }^{\circ} \mathrm{C}$ with rotation set at $400 \mathrm{rpm}$. Later, the temperature was reduced to $60{ }^{\circ} \mathrm{C}$ and rotation was kept at $300 \mathrm{rpm}$ for $2 \mathrm{~h}$. The oil and water mixture was collected and processed as described in "Conventional hydrodistillation" section.

\section{Yield}

The yield of the final extract obtained by the two hydrodistillation methods was calculated using the weight of the seeds and the extract obtained from it.

\section{Gas chromatography-mass spectrometry}

The GC-MS analysis of the extracts was carried on Shimadzu (QP2010 series) gas chromatograph-mass spectrometer (Tokyo, Japan) equipped with an AOC-20i
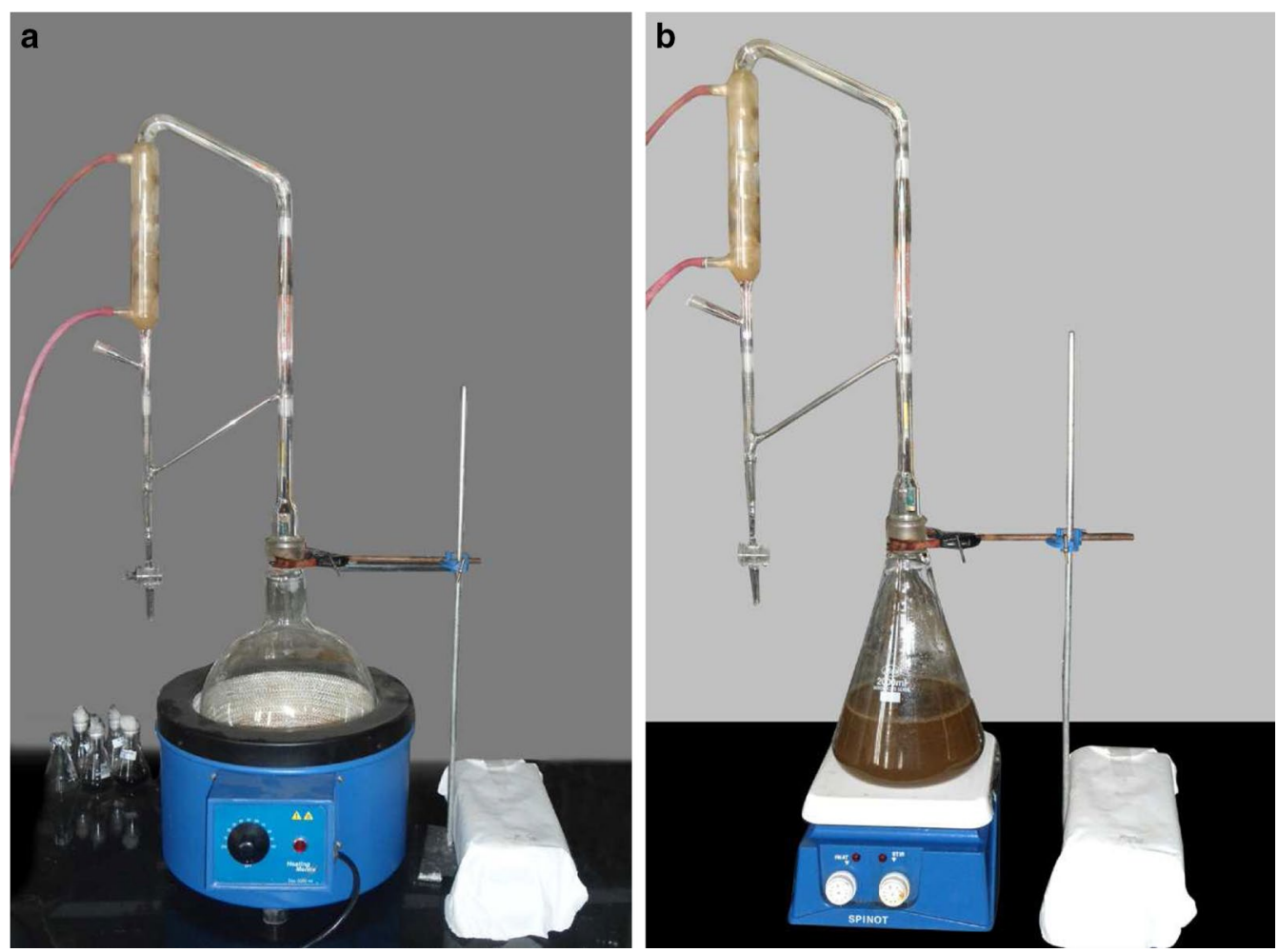

Fig. 1 The different hydrodistillations methods where a conventional method and $\mathbf{b}$ modified method 
auto-sampler coupled to a DB-5 MS capillary column (30 $\mathrm{m} \times 0.25 \mathrm{~mm}$ i.d., $0.25 \mu \mathrm{m})$. The injection temperature was $40^{\circ} \mathrm{C}$ and the volume of the sample was $2 \mu \mathrm{l}$. An initial temperature of $40{ }^{\circ} \mathrm{C}$ was maintained for $4 \mathrm{~min}$, followed by a gradient increase to $230{ }^{\circ} \mathrm{C}$ at the rate of $4{ }^{\circ} \mathrm{C} / \mathrm{min}$ and the temperature was held at $230{ }^{\circ} \mathrm{C}$ for $15 \mathrm{~min}$. Inlet pressure was kept at $97.1 \mathrm{kPa}$ with helium as a carrier gas released at a flow rate of $1.1 \mathrm{ml} / \mathrm{min}$ in split mode (1:50). The MS was set with an interface temperature of $250{ }^{\circ} \mathrm{C}$ at EI mode of MS and the detector voltage of $0.9 \mathrm{kV}$. The mass range was $40-800 \mathrm{u}$ with the scan speed of $1666 \mathrm{u} / \mathrm{s}$ at an interval of $0.50 \mathrm{~s}(2 \mathrm{~Hz})$.

\section{Results and discussion}

The conventional hydrodistillation method gave a yield of $0.825 \%$ with the composition of 4-methylthiobutyl isothiocyanate (erucin) (76.31\%) and butyl isothiocyanate (11.87 \%) (Fig. 2a). Erucin was isolated from the extract, since it is the major GHP of E. sativa (Arora et al. 2014b). The yield obtained was comparatively less with only two hydrolytic products in it. Some compounds other than glucosinolate hydrolytic products were also obtained during the extraction as detected in the extract, which were butylated hydroxytoluene $(9.22 \%)$ and dioctyl adipate $(2.60 \%)$ (Fig. 2a). The composition of hydrolytic

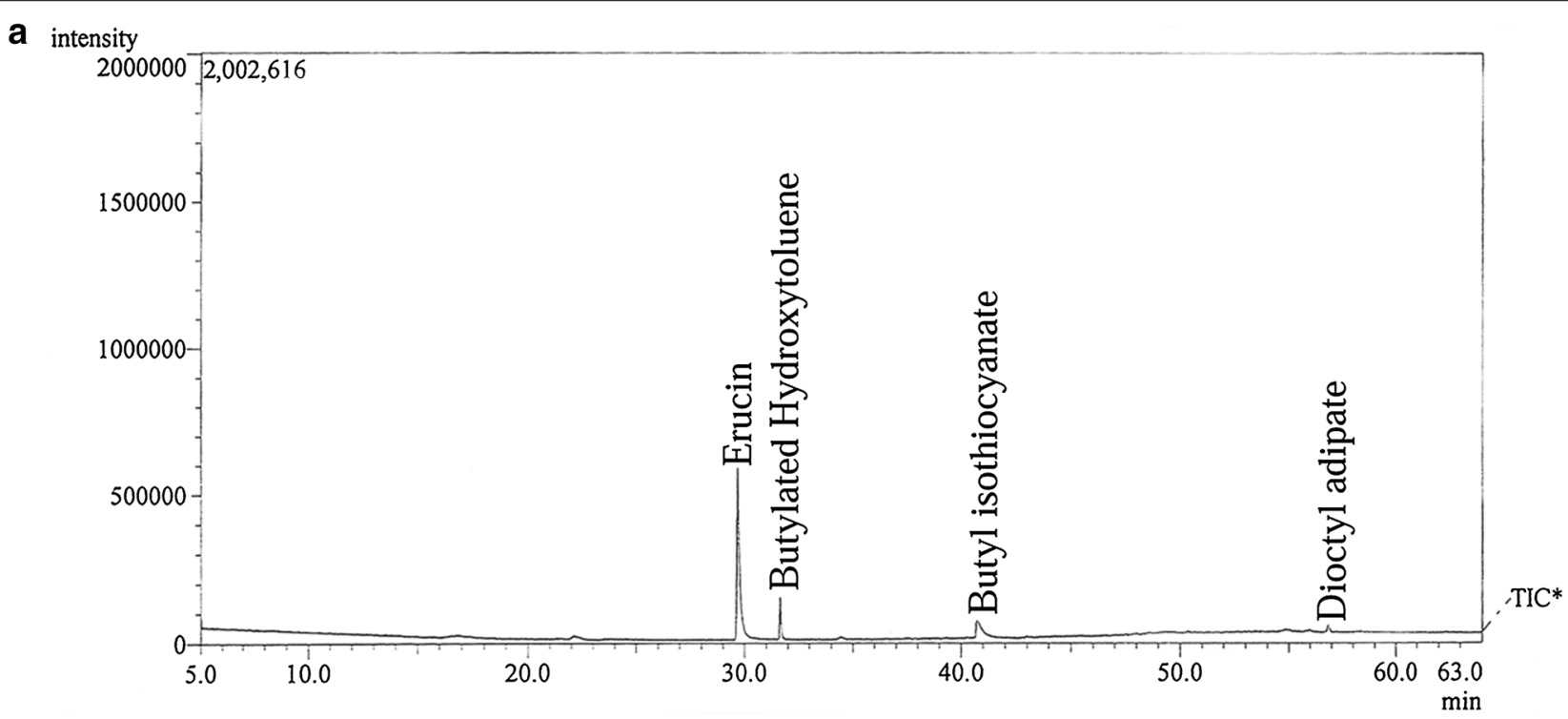

b intensity

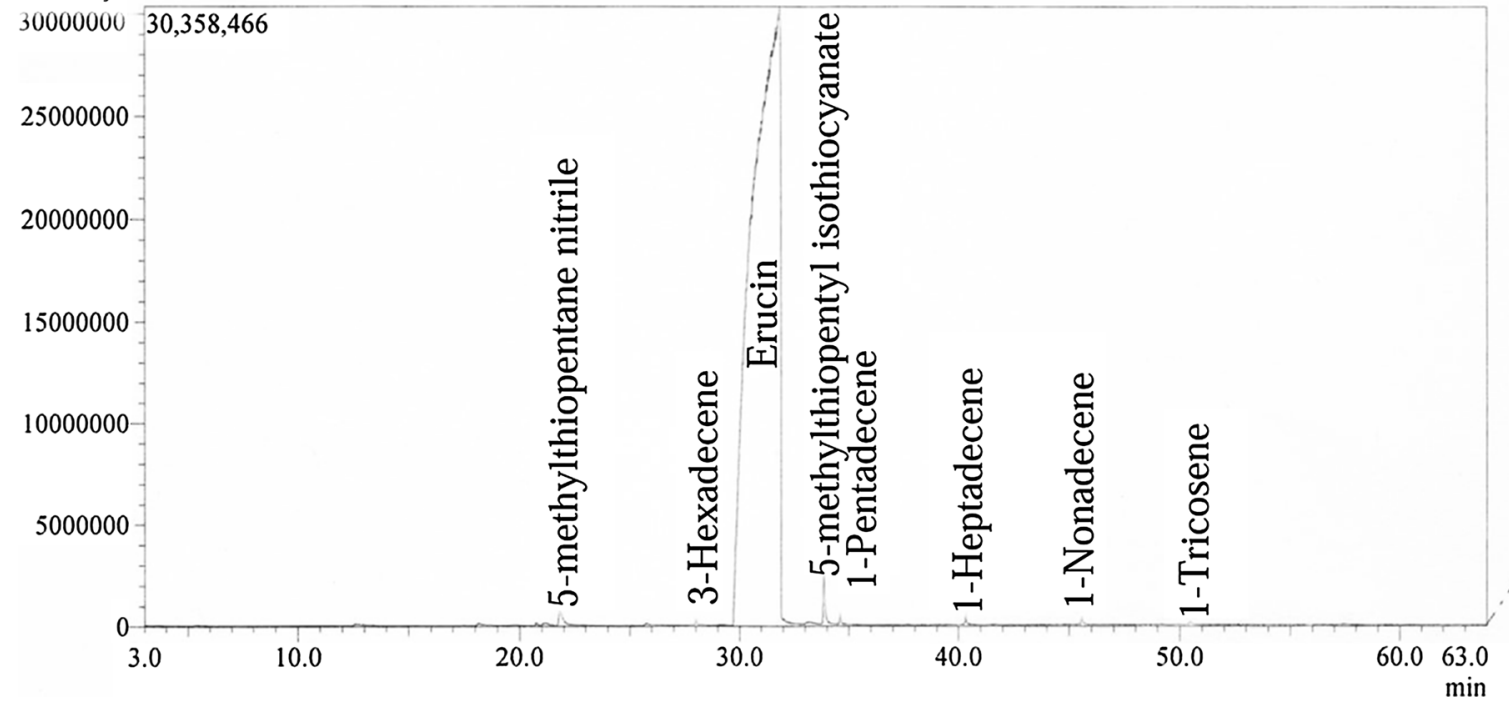

Fig. 2 The GC-MS analysis of the extract, where $\mathbf{a}$ conventional method and $\mathbf{b}$ modified method 
products is only two and in addition the other undesirable compounds (total $11.82 \%$ of extract) present may act in an antagonistic or synergistic way to affect the activity of the extract. The Butylated hydroxytoluene is often used as a food additive and has antioxidative properties (Aourahoun et al. 2014). On the other hand, dioctyl adipate is a plasticizer and is toxic at certain levels (Milkov et al. 1973). These together may hinder the actual activity of the extract and may also cause slight toxicity.

The refined hydrodistillation was designed to solve the major problem of burning of the seeds by stirring the seed mixture. In addition to the mixing, a homogenous supply of heat to the entire mixture was ensured. A yield of $0.910 \%$ was achieved by the modified hydrodistillation method, which was slightly higher than the conventional method. The time required in obtaining the final extract was also reduced. In this case as well, erucin was found to be the major hydrolytic product with the concentration of $98.77 \%$ of the extract. There were two more hydrolytic products present viz. 5-methylthiopentane nitrile $(0.29 \%)$ and 5-methylthiopentyl isothiocyanate (0.57 \%). A few compounds other than the glucosinolate hydrolytic products were also present in the extract viz. 3-hexadecene $(0.06 \%), 1$-pentadecene $(0.10 \%)$, 1-heptadecene $(0.08 \%), 1$-nonadecene $(0.09 \%)$ and 1-tricosene $(0.04 \%)$. The total amount of these undesirable compounds was only $0.37 \%$ of the total extract, which is quite negligible in comparison to the major hydrolytic product. The amount of major hydrolytic product i.e. erucin in the extract, makes it quite suitable for the isolation purpose and thus the current hydrodistillation method can further be employed for obtaining purified compounds.

\section{Conclusion}

The modified hydrodistillation method involving magnetic stirrer with hot plate provided better yield and composition of GHPs in lesser time in contrast to the conventional method. Moreover, the amount of major hydrolytic product i.e. erucin was significantly higher than the conventional method. This in turn simplifies the isolation of an important and biologically active compound, thus making it suitable for laboratory purposes.

\section{Authors' contributions}

RA, BS, APV and SA have made substantial contributions to conception and design of the method. RA and BS were responsible for acquisition, analysis and interpretation of the data. RA was involved in drafting the manuscript. RA, APV and SA were involved in critically revising the manuscript. SA has given final approval of the version to be published. RA, BS, APV and SA have given final approval of the version to be published and agree to be accountable for all aspects of the work in ensuring the questions related to the accuracy or integrity of any part of the work are appropriately investigated and resolved. All authors read and approved the final manuscript.

\section{Author details}

${ }^{1}$ Department of Botanical and Environmental Sciences, Guru Nanak Dev University, Amritsar, Punjab 143005, India. ${ }^{2}$ Natural Plant Products Division, CSIR-Institute of Himalayan Bioresource and Technology, Palampur, Himachal Pradesh 176061, India.

\section{Acknowledgements}

The Director, CSIR-IHBT Palampur, is acknowledged for providing the facilities. Authors would like to acknowledge Department of Science and Technology (DST), New Delhi and University Grants Commission (UGC), New Delhi under the scheme of UPE and CPEPA for their generous funding. We also thank Mrs. Vijaylata Pathania, IHBT, Palampur, for the GC-MS analyses.

\section{Competing interests}

The authors declare that they have no competing interests.

Received: 12 September 2015 Accepted: 16 March 2016

Published online: 18 April 2016

\section{References}

Aourahoun KAK, Fazouane F, Benayad T, Bettache Z, Denni N (2014) The synthetic antioxidant butylated hydroxytoluene, a naturally occurring constituent of the broom Cytisus triflorus L'Hérit. J Nat Prod 7:58-64

Arora R, Vig AP, Arora S (2014a) Glucosinolates: transposing trends of identification methods from paper chromatography to microchip analysis. Int J Life Sci Biotech Pharma Res 3:42-61

Arora R, Sharma D, Kumar R, Singh B, Vig AP, Arora S (2014b) Evaluating extraction conditions of glucosinolate hydrolytic products from seeds of Eruca sativa (Mill.) Thell. using GC-MS. J Food Sci 79:C1964-C1969

Arranz E, Jaime L, de Las Hazas ML, Reglero G, Santoyo S (2015) Supercritical fluid extraction as an alternative process to obtain essential oils with anti-inflammatory properties from marjoram and sweet basil. Ind Crops Prod 67:121-129

Blazevic I, Mastelic J (2009) Glucosinolate degradation products and other bound and free volatiles in the leaves and roots of radish (Raphanus sativus L.). Food Chem 113:96-102

Khoobchandani M, Ojeswi BK, Ganesh N, Srivastava MM, Gabbanini S, Matera $R$, lori R, Valgimigli L (2010) Antimicrobial properties and analytical profile of traditional Eruca sativa seed oil: comparison with various aerial and root plant extracts. Food Chem 120:217-224

Milkov LE, Aldyreva MV, Popova TB, Lopukhova KA, Makarenko YL, Malyar LM, Shakhova TK (1973) Health status of workers exposed to phthalate plasticizers in the manufacture of artificial leather and films based on PVC resins. Environ Health Persp 3:175-178

Patra JK, Kim SH, Baek KH (2015) Antioxidant and free radical-scavenging potential of essential oil from Enteromorpha linza L. prepared by microwave-assisted hydrodistillation. J Food Biochem 39:80-90

Vig AP, Rampal G, Thind TS, Arora S (2009) Bio-protective effects of glucosinolates - a review. LWT Food Sci Technol 42:1561-1572 